\title{
Antimicrobial Evaluation of the Methanol Bark Extracts of Plumbago Dawei Rolfe, A Local Spp. Used By the Samburu Community, Wamba, Samburu District, Kenya for The Treatment Of Diarrheal Ailments
}

\author{
Omori Eric Omwenga $^{1 *}$ and $\underline{\text { Okemo Owour Paul }}{ }^{2}$ \\ ${ }^{1}$ Faculty of Health Sciences, Kisii University College, P.O. Box 408 - 40200, Kisii, Kenya \\ ${ }^{2}$ Plant and Microbial Sciences Department, Kenyatta University, P.O Box 43844-00100, Nairobi, Kenya \\ E.mail: omorieric@gmail.com
}

Received $13^{\text {th }}$ April 2012; Received in revised form $10^{\text {th }}$ May 2012; Accepted $17^{\text {th }}$ May 2012

\begin{abstract}
Aims: The Samburu are a marginalized nomadic people in Kenya who have no access to conventional medical services thus they mainly depend on the medicinal plants for most of their medicare. Antimicrobial activity of the commonly used medicinal plant (Plumbago dawei Rolfe.) by the Samburu community was investigated to verify claims by locals of its medicinal properties.

Methodology and results: The antimicrobial bioassays of the methanol extracts of Plumbago dawei Rolfe was carried out by the disc diffusion method against Staphylococcus aureus - ATCC 20591, Bacillus subtilis- local isolate, Salmonella typhi - ATCC 2202, Escherichia coli- STD-25922 and Pseudomonas aeruginosa - ATCC 25852., By use of the micro dilution method MICs and MBCs were also determined. Preliminary phytochemical screening was done on the extracts. The methanol extracts were highly active against all the test strains. The inhibitory zones ranged from $16 \mathrm{~mm}$ $25.66 \mathrm{~mm}$. The zones of inhibition were not significantly different except for the $E$. coli $(16.33 \mathrm{~mm})$ at $\mathrm{P}<0.05$. The extract showed strong MIC and MBC against S. typhi, S. aureus, E. coli and P. aeruginosa (MIC- $9.38 \mathrm{mg} \mathrm{mL}^{-1}$ and MBC$9.38 \mathrm{mg} \mathrm{mL}^{-1}$ ). Thus the extract was more of bactericidal than bacteriostatic in most test strains. Preliminary phytochemistry revealed presence of flavonoids, tannins and cardiac glycosides.

Conclusion significance and impact of study: The data suggests that methanolic extracts of Plumbago dawei could be a rich source of antimicrobial agents. These results give scientific backing for the use of the Plumbago dawei Rolfe. barks by the Samburu in the treatment of conditions associated with diarrhea and other associated infections caused by the test organisms.
\end{abstract}

Keywords: diarrhea; medicinal plants, phytochemicals, antimicrobial activity

\section{INTRODUCTION}

The Samburu community is one of those communities that are marginalized in Kenya in terms of 'HEALTH CARE FOR ALL' as a basic human right and prerequisite to social-economic development. The frequent use of medicinal plants by the Samburu for health care is as a result of the unavailability of health care services from the government in this remote region of Kenya (Bussmann, 2006; Omwenga et al., 2009). The problem is compounded by high poverty rate, poor sanitary conditions and inadequacy of clean water. For instance, pastoralism is a normal practice of the inhabitants' that leads to sharing of water with both domestic and wild animals. Since the region is neglected, the inhabitants use water without proper treatment as it is scarce most of the year. This has led to an increase in diarrhoreal diseases in the Samburu region (Omwenga et al., 2009).

The Samburu people contribute to the estimated 4.6 million people worldwide, including 2.5 million children, who die from diarrhoeal diseases every year particularly in developing countries (Bryce et al., 2005). In the world diarrhea is the second killer of children after pneumonia related cases. The adults are also affected with an estimated incidence of 1.4 episodes/adult/year (Kosek et al., 2003; Omwenga et al., 2009). Diarrhea is a killer disease worldwide and is amongst the symptoms of many other diseases (Amabeoku, 2009), which makes the need to control diarrhea very urgent.

In recent years, multiple drug resistance in human pathogenic microorganisms has developed due to indiscriminate use of commercial antimicrobials in the treatment of infections (Amabeoku, 2009). It has been noted that microorganisms have the genetic ability to transmit and acquire resistance to antibiotics and have become a major global healthcare problem in the 21st century (Alanis, 2005). These situations are coupled with the undesirable side-effects of certain antibiotics and the emergence of previously uncommon infections. Hence this has forced scientists to search for new antimicrobial substances from various sources including plants (Karaman et al., 2003; Aliero et al., 2008). 
The search for antimicrobials from higher plants is not in vain because it is estimated that over $75 \%$ of the antibacterial drugs in clinical use today are of natural origin (Khoobchandani et al., 2010). Plant derived antimicrobial compounds have been observed to inhibit bacteria through different mechanisms and provide clinical value in the treatment of infections caused by resistant microbes (Stein et al., 2005). Therefore the plants and herbal extracts have found important position in modern medicine, due to their content in natural medicinal compounds. Their secondary metabolites represent a large reservoir of structural moieties which work together, exhibiting a wide range of biological activities. World Health Organization (WHO) estimates that more than 80 $\%$ of the world's population is dependent (wholly or partially) on plant-based drugs (Kuete et al., 2008; Orwa et al., 2008). In East Africa, $90 \%$ of the population relies on traditional medicines and traditional health practitioners as the primary source of health care. There is need therefore to evaluate the herbs scientifically for their antimicrobial activity against the antibiotic-resistant microorganisms, in order to develop complementary phytochemical strategies (Simoes et al., 2009).

Nature's biosynthetic engine produces innumerate secondary metabolites with distinct biological properties that make them valuable as health products or as structural templates for drug discovery (Kishore et al., 2009). In this study, ethnomedical information was collected for a commonly used medicinal plant, Plumbago dawei Rolfe. This medicinal plant was chosen because it is widely available and used by the Samburu community at Wamba, Samburu District-Kenya in the management of various ailments among them being diarrhea related illnesses.

\section{MATERIALS AND METHODS}

\section{Plant material collection, identification and extract preparation}

The barks of Plumbago dawei Rolfe. were collected from Namunyak conservancy-Wamba, Samburu District, Kenya (Figure 1), in September 2007 based on the ethnobotanical survey that was carried out (Omwenga, 2009). The plant was authenticated by a plant taxonomist from the Plant and Microbial Sciences Department, Kenyatta University, Nairobi, Kenya, in whose herbarium the voucher specimen was deposited. The barks were chopped into small pieces, shade dried and grounded using hammer type milling machine (Meecan, CM/L1364548, India). The powdered material was transferred into and extracted in the soxhlet extractor using $80 \%$ methanol (MW-32.04) for $72 \mathrm{~h}$ (Aiyelaagbe and Osamudiamen, 2009). The extracts were filtered through a Whatmann filter paper No. 42 (125 mm) and concentrated using a rotary evaporator (VV 2000 Heidolph, Germany) with the water bath set at $40^{\circ} \mathrm{C}$ (Edeoga et al., 2005)], then dried in a dessicator over anhydrous $\mathrm{CuSO}_{4}$. The powdered residue were transferred into vials and stored at $4{ }^{\circ} \mathrm{C}$ in airtight vials before the bioassays.

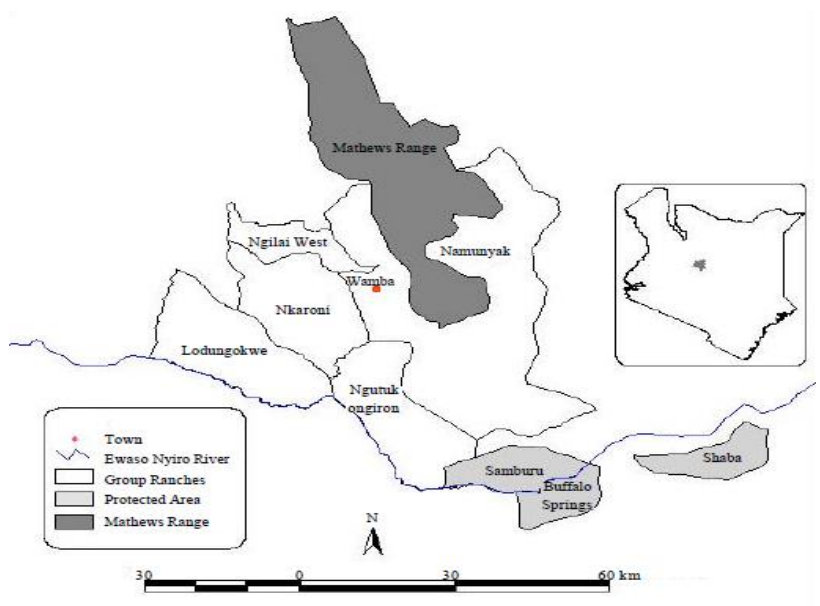

Figure1: Map of Kenya showing the location of Wamba Division and its conservancies

\section{Antimicrobial screening/ bioassay}

Test cultures: Test cultures were obtained from Kenyatta National Hospital in Nairobi-Kenya, which included Staphylococcus aureus (Gram +ve cocci) - ATCC 20591, Bacillus subtillis (Gram +ve spore forming bacilli) - local isolate, Salmonella typhi (Gram -ve rod) - ATCC 2202, Escherichia coli (Gram-ve rod) - STD-25922 and Pseudomonas aeruginosa (Gram-ve rod) - ATCC 25852. All the microorganisms were maintained at $4 \stackrel{\circ}{\circ}$ on nutrient agar slants. Some of the micro organisms were selected on the basis of their natural differences and cell wall properties, but others such as Escherichia coli and Salmonella typhi were identified in Samburu as actual causes of diarrhea (Omwenga et al., 2009).

Disc diffusion method: The antimicrobial bioassay was performed by agar disc diffusion method for methanol extracts (Meite et al., 2009). In the disc diffusion method, Mueller Hinton agar (Biotec) was prepared following the manufacturer's instructions and was inoculated with 100 $\mu \mathrm{L}$ of the inoculum that was prepared by diluting a $24 \mathrm{~h}$ culture of the bacterial type culture or clinical isolate to in normal saline solution to attain a $0.5 \mathrm{McF}$ arland standard. Spread plate method was used to culture $0.1 \mathrm{~mL}$ of the microbial suspension that was introduced into the Petri dishes. Then a paper disc Whatmann No. 43 dry sterile disks (6 $\mathrm{mm}$ diameter) were soaked in the plant extract (made by dissolving $300 \mathrm{mg}$ of the extracts in $1 \mathrm{~mL}$ of methanol) and placed on the spread plates at reasonable distances. Disks were impregnated with methanol and dried (negative control) and various positive controls (amoxicillin-250 mg) were used. The plates were then incubated at $35{ }^{\circ} \mathrm{C}$ for $24 \mathrm{~h}$. The procedure was done in triplicate. Microbial growth was determined by measuring the diameter from the end of growth to the disc at one end to the beginning of growth at the other end including the 
diameter of the disc. The experiment was repeated three times and the mean values recorded.

\section{Determination of the Minimum Inhibitory Concentration (MIC) and Minimum Bactericidal Concentration (MBC)}

A micro-dilution technique using 96 well micro-plates, (Andrews, 2001; Omwenga et al., 2009) was used to obtain MIC values of the crude extracts against all the test bacteria. Each plant extract was serially diluted to obtain a concentration that was ranging from $75 \mathrm{mg} / \mathrm{mL}$ to 18.75 $\mathrm{mg} / \mathrm{mL}$. Similar serial dilutions were performed for Cefrodoxima (250 mg), as a positive control and nutrient broth was used as the negative control. The starting concentration for Cefrodoxima in the first well after the dilution was $75 \mathrm{mg} / \mathrm{mL}$. An equal volume of $50 \mu \mathrm{L}$ fresh bacterial cultures were added to each of the wells. Micro titre-plates were covered and incubated at $37{ }^{\circ} \mathrm{C}$ overnight. The MIC values were determined as the lowest concentrations of the extract showing no growth. All the wells where no growth (not turbid) was observed were sub cultured, and the lowest concentration of the plant extracts that did not yield any colony on the solid nutrient agar after sub-culturing and incubating for $12-24 \mathrm{~h}$ was taken as the MBC. All tests were performed in triplicates.

\section{Phytochemical screening}

Qualitative phytochemical analysis of the crude powder of the plant collected was determined by established methods (Edioga et al., 2005, Jigna and Sumitra, 2007).

\section{Data analysis}

Data was analyzed using the Minitab Statistical Software 13.20, (c) 2000 Minitab Inc. PA 16801-9928, USA. Among the groups, significance test was performed using the one-way ANOVA at $5 \%$ significance level.

\section{RESULTS}

Table 1 shows the disc diffusion results of the methanol extracts of Plumbago dawei Rolfe. The extract was more active on the Gram positive bacteria than the Gram negative bacteria except for Pseudomonas aeruginosa with very high zones of inhibition. The zones of inhibition were not significantly different except for the $E$. coli at $\mathrm{P}_{<}$ 0.05 against those produced by the positive control. All the zones of inhibition were $\geq 9.00 \mathrm{~mm}$ which made it possible to proceed to MICs and the MBCs. For the negative control no zone of inhibition was observed (6 $\mathrm{mm})$.

Table 2 shows the Minimum inhibitory/bactericidal concentrations (MIC and MBC) of the methanolic extract of Plumbago dawei Rolfe. against S. typhi, B. subtilis, $S$. aureus, $E$. coli and $P$. aeruginosa. The extracts showed strong MICs and MBCs $(9.38 \mathrm{mg} / \mathrm{mL}$ respectively) against $S$. typhi, S. aureus, E. coli and P. aeruginosa. Thus the extracts were more of bactericidal than bacteriostatic in all the test strains. The extracts produced lower inhibitory concentration than the positive control except for $P$. aeruginosa where the MIC and MBC concentration was the same $(9.38 \mathrm{mg} / \mathrm{mL}$ respectively) as that of the positive control.

Table 1: Antimicrobial activity (Diameter of inhibition zone in $\mathrm{mm}$ ) of bark extracts of Plumbago dawei Rolfe

\begin{tabular}{llll}
\hline Microorganism & Extract & $\begin{array}{l}+\mathbf{v e} \\
\text { control }\end{array}$ & $\begin{array}{l}\text {-ve } \\
\text { control }\end{array}$ \\
\hline Staphylococcus aureus & 25.66 & 18.66 & 6.00 \\
Bacillus subtillis & 24 & 17.33 & 6.00 \\
Salmonella typhi & 16.00 & 16.66 & 6.00 \\
Escherichia coli & 16.33 & 15 & 6.00 \\
Pseudomonas aeruginosa & 21.66 & 23.33 & 6.00 \\
\hline Key: Positive controls- Amoxicillin for S. aureus, B. \\
subtilis, S. typhi, E. coli and P. aeruginosa. Negative \\
control- dried methanol discs. Values are means of \\
triplicates
\end{tabular}

From the preliminary phytochemistry screening, the Plumbago dawei extract tested positive for tannins, flavonoids and Cardiac glycosides (Table 3). Saponins, terpenoids and alkaloids were absent.

\section{DISCUSSION}

From the study, the activity of Plumbago dawei Rolfe. extracts against test strains showed that the plant contains pharmacologically active properties (Table 1). Usually a zone of inhibition $\geq 9.00 \mathrm{~mm}$ is an indication of strong antimicrobial activity (Rani and Khullar, 2004). Our data shows in general that the extract had strong antibacterial activity against both Gram-positive test and Gram-negative test cultures. This is because the extract produced zones of inhibition that are greater than 9.00 $\mathrm{mm}$ in diameter. The extract produced wider inhibition zones against Staphylococcus aureus (25.66 $\mathrm{mm}$ ) and Bacillus subtilis (24 mm) than their counterparts i.e. Gram negative isolates. These zones of inhibition were not significantly different except for $E$. coli at $\mathrm{P}<0.05$. The activity of the extract could be ascribed to the cell wall properties i.e. unlike Gram-positive bacteria, the lipopolysaccharide layer along with proteins and phospholipids are the major components in the outer surface of Gram-negative bacteria and could have played a big role towards the general permeability of the two cell walls to the extracts (Govindarajan et al., 2008).

Minimum Inhibitory Concentrations and minimum bactericidal concentrations produced by the extract against various bacterial test cultures showed strong antimicrobial activity also (Table 2). The findings clearly demonstrates that the methanol extract has more of the bactericidal properties than bacteriostatic since the extract inhibited growth of the test strains at similar concentrations of both MIC and MBC (9.38 mg/mL respectively) except for Bacillus subtillis. This concentration was similar to that produced by the positive 
Table 2: Minimum inhibitory/bactericidal concentrations $(\mathrm{mg} / \mathrm{mL})$ of the bark extracts of Plumbago dawei Rolfe.

\begin{tabular}{lcccccc}
\hline Microorganism & \multicolumn{2}{c}{ Extract } & \multicolumn{2}{c}{ Positive controls } & Negative control \\
\cline { 2 - 6 } & MIC & MBC & MIC & MBC & MIC & MBC \\
\hline Staphylococcus aureus & 9.38 & 9.38 & 18.75 & 18.75 & \\
Bacillus subtilis & 9.38 & 18.75 & 18.75 & 18.75 & \\
Salmonella typhi & 9.38 & 9.38 & 18.75 & 18.75 & Growth observed in all tubes \\
Escherichia coli & 9.38 & 9.38 & 18.75 & 18.75 & \\
Pseudomonas aeruginosa & 9.38 & 9.38 & 9.38 & 9.38 & & \\
\hline
\end{tabular}

Key: Positive controls - Cefrodoxima for S. aureus, B. subtillis, S. typhi, E. coli and P. Aeruginosa; Negative control Nutrient Agar

Table 3: The Plumbago dawei Rolfe. Phytochemical screening test result

\begin{tabular}{lc}
\hline Phytochemical & Concentration \\
\hline Tannins & ++ \\
Saponins & - \\
Flavonoids & ++ \\
Terpenoids & - \\
Cardiac glycosides & + \\
Alkaloids (Wagner's test) & - \\
\hline
\end{tabular}

control against the test isolates. These results suggest that the Plumbago dawei Rolfe. could be very promising in the treatment of bacterial related illnesses. Among the Gram negative test strains, the highest activity was observed in $P$. aeruginosa. This was a good finding as $P$. aeruginosa is known to be difficult to be controlled by the commonly used antibiotics because of the cell wall properties (Omwenga et al., 2009). Similar activity of the extract and the positive control was observed for $S$. typh and $E$. coli test cultures. These were also a good finding since these test cultures have been found to be the main pathogens for diarrhea in the Samburu community (Omwenga et al., 2009). It clearly demonstrates that the extract could be having modes of action which may help to combat some of the diseases that are caused by these Gram negative bacteria.

This activity of the Plumbago dawei may be due to the presence of the screened phytochemicals and those that may be present but whose presence is not known (Table 3). The extract was found to possess flavonoids, tannins and cardiac glycosides among the screened phytochemicals. Flavonoids have been known to form complexes with bacterial cell wall, therefore inhibiting microbial growth (Kuete et al., 2008). Also flavonoids (catechins) have been reported to have antibacterial activity by inhibiting the action of DNA polymerase (Chakraborty and Chakraborti, 2010). On the other hand tannins have been reported to have bacteriostatic or bactericidal activities against Gram positive and Gram negative bacteria (Akiyama et al., 2001). The tannins do disrupt the cell membranes of the microorganisms by denaturing, hence inhibiting their growth (Akiyama et al., 2001). The activity of the extract may also be due to the synergistic activity of the phytochemicals that were found to be present and those that are yet to be known (Ruttoh et al., 2009). The ability of Plumbago dawei to be sensitive to both Gram positive and Gram negative bacteria is a clear indication of its broad spectrum antimicrobial activity.

\section{CONCLUSION}

community for usage of the Plumbago dawei in the treatment of diarrhoeal diseases since the extracts were active against the test cultures especially the ones known to cause diarrhea in the community. However, the mechanism of action of the constituents of Plumbago dawei extracts may be difficult to speculate irrespective of the fact that they are likely to provide biologically active constituents which may serve as alternatives to the presently less effective antimicrobials. Thus further studies on the in vivo activity, isolation and structural elucidation of the active component(s) and toxicological studies of the plant extract are recommended.

\section{ACKNOWLEDGEMENT}

The authors are grateful to the Earthwatch Institute for sponsoring the project and the Earthwatch volunteers from many parts of the world who took their time to join in the collection of information. Most sincere gratitude also goes to local informants and healers like Margaret Nawamarrian, Samuel Legalgoroule, Benjamin Lekarkaraule, and Lekutuka amongst many who shared their knowledge on the use of medicinal plants with us; as well as Mr. Tom Owuor who assisted in plant collection as an intern student. We are also grateful to Philip Loitore a Laboratory Technologist at Wamba Catholic Hospital for the enormous assistance he gave to the project. Special thanks finally go to Wamba Catholic Hospital, Samburu for accepting and giving us bench space for the laboratory work and to Kenyatta University where finer details of the work were concluded.

\section{REFERENCES}

Aiyelaagbe, O.O. and Osamudiamen, P.M. (2009). Phytochemical screening for active compounds in Mangifera indica leaves from Ibadan, Oyo State. Plant Science Research. 2(1): 11-13.

Akiyama, H., Fujii, K., Yamasaki, O., Oono, T. and Iwatsuki, K. (2001). Antibacterial activity of several tannins against Staphylococcus aureus. Journal of Antimicrobial Chemotherapy. 48: 487-491.

Alanis, A.L. (2005). Resistance to antibiotics: Are we in the post-antibiotic era? Archives of Medical Research 36: 697-705. 
Aliero, A. A., Aliero, B.L. and Buhari, U. (2008). Preliminary phytochemical and antibacterial screening of Scadoxus multiflorus. nternational Journal of Pure and Applied Sciences. 2(4):13-17

Amabeoku, G.J. (2009). Antidiarrhoeal activity of Geranium incanum Burm. f. (Geraniaceae) leaf aqueous extract in mice Journal of Ethnopharmacology. 123: 190-193.

Andrews, J.M. (2001). Determination of minimum inhibitory concentrations. Journal of Antimicrobial Chemotherapy. 48: 5-16.

Bryce. J., Boschi-Pinto, C. and Shibuya, K. (2005). The WHO Child Health Epidemiology Reference Group. WHO estimates of the causes of death in children. Lancet 365:1147-1152

Bussmann, R.W. (2006). Ethnobotany of the Samburu of Mt. Nyiru, South Turkana, Kenya. Journal of Ethnobiology and Ethnomedicine 2: 35.

Chakraborty, D. and Chakraborti, S. (2010). Bioassayguided isolation and identification of antibacterial and antifungal component from methanolic extract of green tea leaves (Camellia sinensis). Research Journal of medicinal plant. 4(2): 78-86.

Edeoga, H.O., Okwu, D.E. and Mbaebie, B.O. (2005). Phytochemical constituents of some Nigerian medicinal plants. African Journal of Biotechnology. 4 (7): 685-688

Govindarajan, M., Jebanesan, A., Reetha, D., Amsath, R, Pushpanathan, T. and Samidurai, K. (2008). Antibacterial activity of Acalypha indica L. European Review for Medical and Pharmacological Sciences, 12: 299-302

Jigna, P. and Sumitra, V. C. (2007). In vitro Antimicrobial activity and phytochemical analysis of some Indian medicinal plants. Turkey Journal of Biology 31:53-58.

Karaman, Y., Sahin, F., Gulluce, M., Ogutcu, H., Sengul, M. and Adiguzel, A. (2003). Antimicrobial activity of aqueous and methanol extracts of Juniperus oxycedrus L. Journal of Ethnopharmacology.85: 213-235.

Khoobchandania, M., Ojeswi, B.K., Ganesh, N., Srivastava, M.M., Gabbanini, S., Matera, R., lori, R. and Valgimigli, L. (2010). Antimicrobial properties and analytical profile of traditional Eruca sativa seed oil:Comparison with various aerial and root plant extracts. Food Chemistry. 120: 217-224

Kishore, N., Mishra, B.B., Tripathi,V. and Tiwari, V.K. (2009). Alkaloids as potential anti-tubercular agents. Fitoterapia. 80:149-163.

Kosek, M., Bern, C.and Guerrant, R.L. (2003). The global burden of Diarrhoeal disease, as estimated from studies published between 1992 and 2000. Bull World Health Organisation. 81: 197-204.

Kuete, V., Ngameni, B., Simo, C.C.F., Tankeu, R.K., Ngadjui, B.T., Meyer, J.J.M., Lall, N. and Kuiate, J.R. (2008). Antimicrobial activity of the crude extracts and compounds from Ficus chlamydocarpa and Ficus cordata (Moraceae). Journal of Ethnopharmacology. 120:17-24.
Meite, S., N'guessan, D., Bahi, C., Yapi, H.F., Djaman, A.J. and Guina, F.G. (2009). Anti-diarrheal Activity of the Ethyl Acetate Extract of Morinda morindoides in Rats. Tropical Journal of Pharmaceutical Research 8 (3): 201-207.

Omwenga, E.O. (2009). Ethnobotanical survey, antimicrobial efficacy and preliminary phytochemical screening of selected anti-diarrhoeal medicinal plants used by the Samburu community, Wamba, Samburu district, Kenya. MSC thesis. Kenyatta universityKenya.

Omwenga, E.O., Okemo, P.O., Mbugua, P,K. and Ogol, C.K.P. (2009). Ethnobotanical survey and antimicrobial evaluation of medicinal plants used by the Samburu community (Kenya) for treatment of diarrhoea. Pharmacognosy magazine. 4 (18): 165176.

Orwa, J.A., Jondiko, I.J.O., Minja, R.J.A. and Bekunda, M. (2008). The use of Toddalia asiatica (L) Lam. (Rutaceae) in traditional medicine practice in East Africa. Journal of Ethnopharmacology. 115: 257-262.

Rani, P. and Khullar, N. (2004). Antimicrobial evaluation of some medicinal plants for their anti-enteric potential against multi-drug resistant Salmonella typhi. Phytotherapy Research.; 18: 670-673.

Ruttoh, E.K., Tarus, P.K., Bii, C.C., Machocho, A.K., Karimi, K.L. and Okemo, P.O. (2009). Antibacterial activity of Tabernaemontana stapfiana BRITTEN (Apocynaceae) extracts. African Journal of Traditional, Complementary and Alternative Medicines. 6 (2): 186-194

Simoes, M., Bennett, R.N. and Rosa, E.A.S. (2009). Understanding antimicrobial activities of phytochemicals against multidrug resistant bacteria and biofilms. Natural Product Reports. 26(6): 746757.

Stein, A.C., Sortino, M., Avancini, C., Zacchino, S. and Von, P.G. (2005). Ethno veterinary medicine in the search for antimicrobial agents: Antifungal activity of some species of Pterocaulon (Asteraceae). Journal of Ethnopharmacology. 99: 211-214. 